\title{
¿Rutinas caseras o fiestas comunitarias? Tafonomía y remontaje de la cerámica calcolítica de El Ventorro (Madrid)
}

\author{
Domestic chores or community feasts? A taphonomic and re-fitting \\ approach to the Chalcolithic ceramics from El Ventorro (Madrid, Spain)
}

\author{
Antonio Blanco González \\ Department of Archaeology, Durham University, \\ Durham, South Road DH1 3LE (Reino Unido) \\ ablancoglez@gmail.com
}

Recibido: 28-11-2013

Aceptado: 08-01-2014

\begin{abstract}
RESUMEN
Comprender cómo llegaron los restos de cultura material al registro arqueológico es un asunto desatendido en la Prehistoria Reciente peninsular, aunque su discusión debería ser previa a cualquier interpretación espacial y funcional. Este artículo presenta un protocolo de análisis para caracterizar las pautas de rotura, representación y erosión de la cerámica prehistórica. La muestra de cerámica selecta de la campaña de 1981 en El Ventorro ha servido como estudio de caso para ensayar la caracterización tafonómica y el remontaje de fragmentos de un contexto inusualmente rico en desechos: la denominada 'cabaña 013'y las fosas anexas. Ello ha permitido contrastar las diversas hipótesis planteadas sobre su génesis y significado: bien tratarse de una vivienda semiexcavada con restos en posición primaria acumulados lentamente o bien estar ante una zanja colmatada de forma rápida con vertidos voluminosos, fruto de repetidas celebraciones multitudinarias. Los resultados no son concluyentes, pero permiten descartar su lectura como suelos de ocupación fosilizados representativos de los enseres y actividades domésticas. Todo apunta a que fue un segmento de foso colmatado con un agregado acumulativo y muy parcial de restos, algunos recién desechados mezclados con residuos secundarios exhibiendo gran variabilidad en su temporalidad e historias deposicionales.
\end{abstract}

Palabras clave: Formación de conjuntos, Remontaje cerámico, Tafonomía cerámica, Estructuras negativas, Calcolítico, Meseta.

\begin{abstract}
The understanding of how cultural remains entered the archaeological record has been a neglected topic in the research on later prehistory in Iberia, even though its discussion should be addressed in advance of any functional or spatial account. This paper presents an analytical protocol designed to characterize the patterns of breakage, abrasion and representation of prehistoric pottery. A taphonomic and re-fitting operation has been carried out with the selected ceramic assemblage retrieved in 1981 from an unusual residue-rich context: the so-called 'pit-hut 013 ' and its annexed pits at El Ventorro. This has allowed to test divergent hypotheses about its formation processes and meaning. This sunken feature has been interpreted either as a pithouse filled with domestic remains in primary context or as a gully quickly filled with bulky refuse as a result of repeated collective celebrations. The results are inconclusive, but allow to reject the idea of being dealing with fossilized occupation soils representative of house-floors and domestic activities. All lines of evidence point to this feature actually being a ditch segment filled with a very partial and cumulative aggregate of freshly discarded remains mixed with secondary residues exhibiting great variability in their temporalities and depositional histories.
\end{abstract}

KEY words: Assemblage formation, Ceramic re-fitting, Ceramic taphonomy, Sunken features, Chalcolithic, Iberian Meseta.

Sumario 1. Introducción. 2. El Ventorro y sus interpretaciones. 3. Metodología de estudio. 4. Caracterización de la muestra cerámica. 5. Discusión. 6. Conclusiones y perspectivas. 


\section{Introducción}

Cualquier estudio científico social ha de asumir ciertas premisas $-\mathrm{y}$ prescindir de otras- para describir y manejar la evidencia factual en que se basa. La Arqueología no es una excepción, y algunos autores vienen denunciando una desconexión entre el repertorio material -lo que se encuentra- y su interpretación teórica -lo que se dice- (Johnson 2006; Lucas 2012: 2-5). Este problema afecta al estudio de la Prehistoria Reciente peninsular, cuyas lecturas socioeconómicas han avanzado a paso de gigante, mientras el tratamiento de su corpus artefactual no se ha renovado al mismo ritmo. Como consecuencia, una base empírica procesada desde principios inadecuados se aleja cada vez más de los argumentos construidos sobre ella. Traslademos esta contrariedad al estudio de su material arqueológico por excelencia: la cerámica. $\mathrm{Su}$ presentación suele centrarse en atributos morfo-tipológicos y hasta tecnológicos (p.e. Priego y Quero 1992; Fabián García 2006; Carmona Ballestero 2013). Ello demuestra un arraigado interés por la periodización y la funcionalidad de los utensilios prehistóricos. Sin embargo, demasiadas veces se descuida -por considerarse evidente o irrelevante- la información sobre la composición total de la muestra estudiada, su representatividad y estado de conservación; en definitiva, aquellos aspectos que permitirían entender cómo lo encontrado ha llegado a formar parte del registro arqueológico.

En este trabajo ${ }^{1}$ se reestudia una colección cerámica calcolítica ya publicada, la del yacimiento madrileño de El Ventorro (Priego y Quero 1992). Este sitio, conocido por sus notorios hallazgos campaniformes, ha suscitado lecturas divergentes (Priego y Quero 1992; Díaz-delRío 2001: 237-250, Garrido Pena 2000: 43-44). Partiendo de las carencias señaladas, el artículo propone una estrategia para recopilar información sobre su ciclo formativo (Jiménez Jáimez 2008) como requisito previo a cualquier interpretación. Se presenta un protocolo de caracterización tafonómica y los resultados de esta experiencia, aplicada a una colección cuyo registro, si bien fue riguroso, responde a las premisas y cuestiones planteadas en 1981. A pesar de las limitaciones del caso analizado, el examen de las pautas de representación, rotura, remontaje y erosión de la cerámica selecta ha permitido evaluar su conciliación con varias propuestas interpretativas. Si bien las conclusiones obtenidas sólo pueden ser tentativas, el experimento permite descartar razonablemente algunos presupuestos barajados hasta ahora, especialmente el pretendido reflejo de las actividades y enseres habituales en el interior de una cabaña de la época. Por encima de sus resultados concretos, el trabajo pretende mostrar el inusitado potencial de este enfoque si se integra en el diseño de futuras investigaciones arqueológicas de campo.

\section{El Ventorro y sus interpretaciones}

El Ventorro o Arenero de Adrián Rosa se localiza en la zona sur del actual término municipal de Madrid, distrito de Villaverde Bajo lindando con Getafe (Fig. 1). El yacimiento se encontraba sobre una suave elevación que forma la terraza media del río Manzanares en su margen derecha, destacando unos $8 \mathrm{~m}$ sobre la llanura aluvial inmediata, próximo a un acusado meandro del río y limitado por el sur por el arroyo Butarque (Fig. 1A). El entorno de ribera del Manzanares se encuentra muy desfigurado por la explotación de áridos, la urbanización y construcción de infraestructuras, pero a lo largo del mismo se conocen numerosos yacimientos prehistóricos (Priego y Quero 1983; Muñoz 1999; Blasco y Baena 2002; Ríos 2011). El yacimiento hoy día está severamente afectado por la carretera M-301, por la depuradora de Butarque y varias edificaciones. Este sitio de época calcolítica fue objeto de sucesivas campañas de excavaciones de urgencia (1963, 1972, 1977 y 1981) (Fig. 1B) previas al funcionamiento de la arqueología preventiva impulsada desde la administración autonómica. Tales trabajos depararon abundantes y llamativas evidencias, como restos muy explícitos de actividades de subsistencia y artesanales o un destacado lote de cerámicas campaniformes de estilo Ciempozuelos, todo ello en el interior de varias cubetas longitudinales y fosas.

$\mathrm{Su}$ temprana investigación y la difusión preliminar de los resultados (Quero y Priego 1975, 1978: 88-90; Priego y Quero 1977: 268-270, 1983: 289-308), incluso en el ámbito internacional (Harrison et al. 1975; Harrison 1977: 178-180), dotaron al lugar de un indudable renombre en la literatura arqueológica. Durante años fue considerado el único hábitat excavado asociado a numerosas cerámicas campaniformes, algunas de ellas empleadas como crisoles en actividades metalúrgicas. La publicación definitiva de la memoria de excavaciones (Priego y Quero 1992) representó un hito para la Prehistoria Reciente regional (Blasco et al. 1994; Garrido Pena 2000: 43-44; Díaz-del-Río 2001: 237-250; Blasco et al. 2011; Liesau et al. 2013: 141). Aquellos trabajos de campo exhumaron $228 \mathrm{~m}^{2}$ en cuatro catas próximas del mismo sector del yacimiento -las tres últimas 


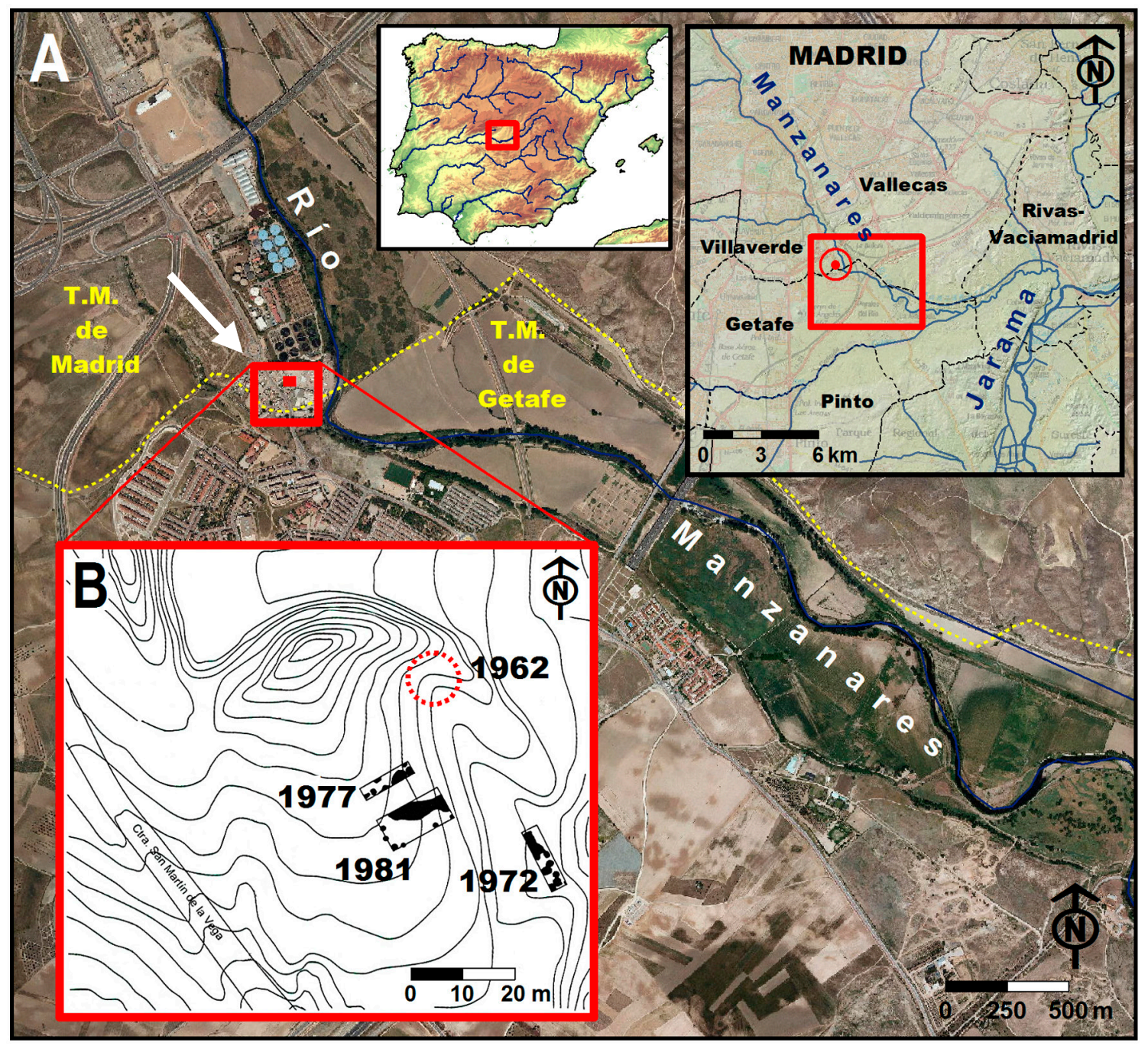

Figura 1.- Localización de El Ventorro en el interior de la Península Ibérica y en el entorno del Manzanares. B. Situación de las catas sobre isohipsas (Díaz-del-Río 2001: 240, fig.61, modificado).

distantes apenas 5 y $15 \mathrm{~m}$ entre sí-, habiéndose documentado en total tres cubetas longitudinales excavadas en el sustrato -interpretadas como "fondos de cabaña"- y 23 fosas o "fondos" en sus inmediaciones. Cuando se efectuaron las excavaciones en este lugar el conocimiento sobre el Calcolítico del interior peninsular era aún muy precario. La exhaustiva y completa memoria de los trabajos (Priego y Quero 1992) recoge algunas de aquellas interpretaciones. Para sus excavadores El Ventorro fue un hábitat sedentario abierto y sin delimitaciones, formado por la agrupación de cabañas. Estas serían construcciones semiexcavadas, con alzados de cañas y barro y techumbre vegetal, que contenían infraestructuras y áreas de actividad interiores -solados, pies de postes, hogares, hornos y talleres de industria lítica, ósea y metalúrgica-, rodeadas de "fondos" auxiliares de uso múltiple -barreros de arcilla, despensas, pozos, estercoleros, basureros (Priego y Quero 1992: 118). Los suelos de ocupación de estas viviendas, de tierra apelmazada, habrían sido limpiados y mantenidos de forma periódica, acumulándose los desechos cotidianos en los vertederos excavados al exterior (Priego y Quero 1992: 118). Así pues, el material remanente dentro de las chozas serían los utensilios aún utilizables y no descartados de la última ocupación, es decir, desechos de facto (Schiffer 1987: 89-96). Tal poblado permanente y populoso habría sido ocupado de forma ininterrumpida durante doscuatro generaciones, dando lugar a dos fases 
superpuestas, coincidentes con las dos etapas -precampaniforme y campaniforme- en que entonces se desglosaba el Calcolítico peninsular (Priego y Quero 1992: 357-364). Sin embargo, desde el saber acumulado en las dos últimas décadas, algunas de aquellas interpretaciones hoy pueden releerse en otro sentido. Para ilustrar mejor este punto vamos a centrarnos en la cata de 1981, la de mayor extensión (Fig. 2), que rindió unos testimonios que han concitado cierta controversia.

En aquella tercera campaña (Priego y Quero 1992: 83-125; Díaz-del-Río 2001: 243-245) se exhumaron cinco fosas -Fondos 008, 009, 010, 011 y 012 - y una zanja de planta alargada excavada en unos $16 \mathrm{~m}$, de sección muy irregular, $4 \mathrm{~m}$ de anchura y 1,2 $\mathrm{m}$ de espesor, denominada “cabaña 013". Este socavón estaba colmatado de lechos cenicientos y arenosos interpretados como las plantas y rellenos consecutivos -sin hiato- de dos chamizos al estilo de los chozos pastoriles, parcialmente superpuestos y reemplazando el uno al otro en un lapso de pocos años (Priego y Quero 1992: 104-105). La ocupación superior sería de época campaniforme -niveles 1 a 5 , que desbordan la planta del socavón-sobre otra previa precampaniforme. Dentro de la "vivienda superior" sus excavadores refieren la existencia de encachados de cerámica, un hogar, un horno metalúrgico con subproductos de fundición de cobre, un recinto circular de piedras en seco y zonas de actividad como un obrador de talla lítica, además de frecuentes pellas de barro con improntas (Priego y Quero 1992: 103-104 y 123125, Láms. XX-XXII). Por su parte, la "vivienda inferior" contaría con otro taller lítico y un par de hogares (Priego y Quero 1992: 104-105 y 124, Lám. XXI, 1). Con posterioridad diversos autores han aceptado esta lectura, considerando que la cata de 1981 muestra un "fondo de cabaña" propio de un poblado de época campaniforme (Blasco et al. 1994; Garrido Pena 2000: 43-44, 1997: 190; Rojo et al. 2005: 525). Ello ha repercutido en algunas lecturas socioeconómicas sobre el final del Calcolítico, al entenderse que la cabaña 013, más amplia que el resto de viviendas, acumulaba campaniformes junto a indicios de actividad metalúrgica y abundantes restos de ganado adulto, explotado por sus "productos derivados" (Garrido Pena 1997: 202; Harrison y Mederos 2001: 121).

Frente a esta línea argumental, Díaz-del-Río (2001: 237-250 y 377-378, Anexos 19 y 20) efectuó en su investigación doctoral un análisis crítico de la información publicada y concluyó ofreciendo una interpretación distinta del sitio y su dinámica

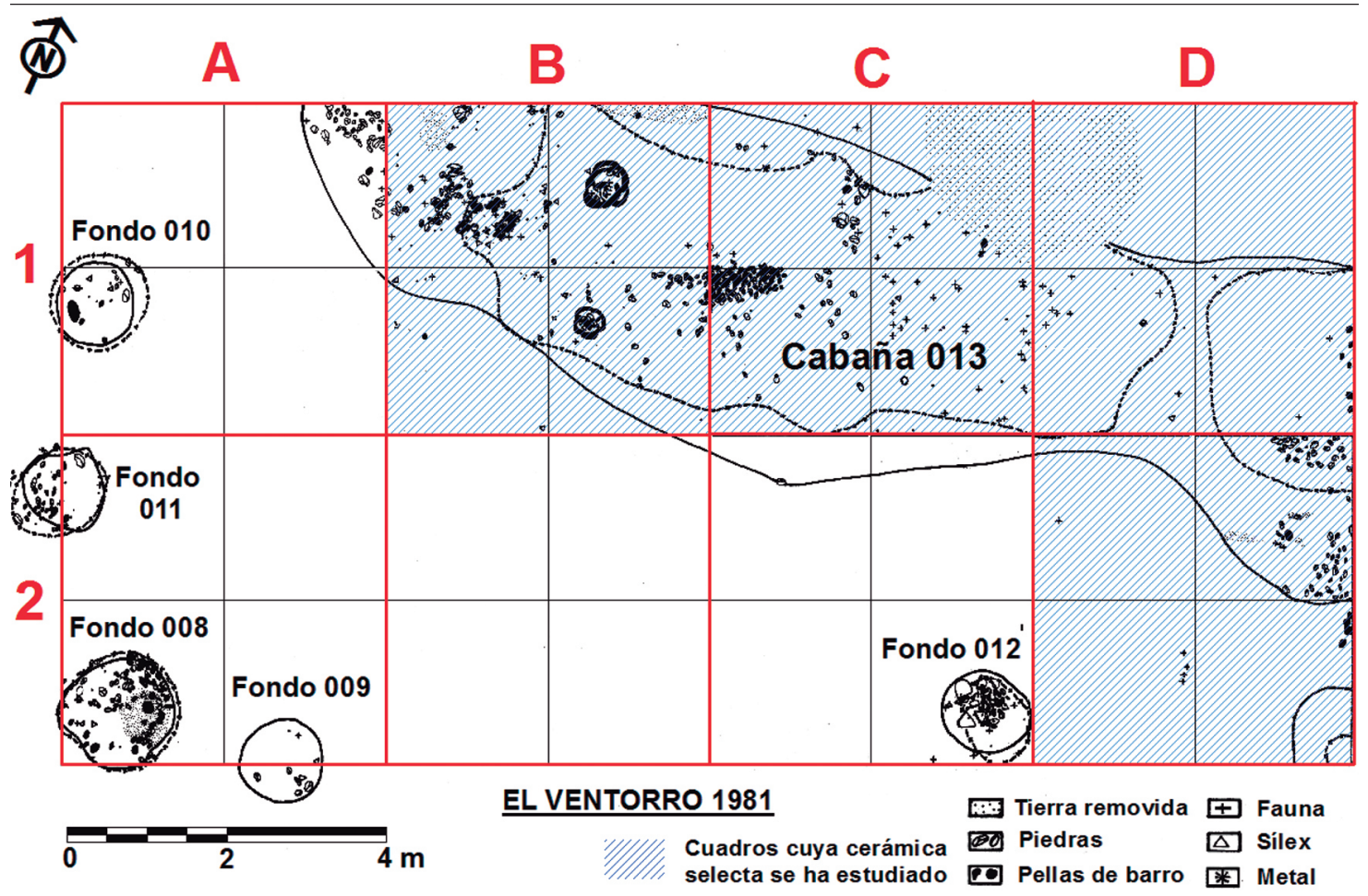

Figura 2.- Cata de 1981 en El Ventorro y cuadros cuya cerámica se ha estudiado (a partir de Priego y Quero 1992: 85, Fig. 32). 
de formación. Sus principales objeciones son: a) la secuencia de dos fases calcolíticas de la cabaña 013 queda invalidada por haberse establecido sobre criterios arbitrarios: la excavación no estratigráfica por alzadas de profundidad preestablecida $(10 \mathrm{~cm})$, que seccionaron distintos sedimentos -afectando a claros lentejones inclinados (Priego y Quero 1992: 101, fig. 39 y 103, fig. 41)- y una discriminación de fases basada sólo en la presencia/ausencia de campaniforme y metalurgia (Díaz-del-Río 2001: 244-245); b) considera que no existen elementos estructurales diagnósticos del ámbito doméstico y los que aparecen, como un hogar asociado a un posible paravientos, indicarían más bien actividades al aire libre (Díaz-del-Río 2001: 246247); c) el desarrollo estratigráfico de la cabaña 013 sería coherente con vertidos consecutivos de grandes volúmenes de desechos, "los restos fragmentados no fueron arrojados fuera, sino más bien abandonados in situ, sin que posteriormente se evidencie ni limpieza, ni un excesivo trasiego que modificase su disposición" (Díaz-del-Río 2001: 247); d) en consecuencia, y a la vista de la extraordinaria cantidad y el cariz de los restos acopiados en la cabaña 013, propuso interpretar dicha acumulación como un vertido paulatino y reiterado de desechos, un midden resultante de actividades festivas (Díaz-del-Río 2001: 248-250, 2006: 73).

En resumen, se han ofrecido interpretaciones diversas y en algunos puntos incluso opuestas sobre la génesis de los restos descubiertos en El Ventorro en 1981. Para sus excavadores se trataría de niveles de ocupación formados en el interior de cabañas techadas, que pese a su limpieza periódica, conservaban in situ estructuras y áreas de actividad doméstica, además de despojos caídos o desplazados, pero todo ello en su contexto utilitario original (Priego y Quero 1992: 83-125). Por el contrario, se ha sugerido que tales restos pudieran responder al abandono al aire libre de grandes cantidades de residuos de forma paulatina, fruto de celebraciones comunitarias periódicas (Díaz-del-Río 2001: 246-250). El objetivo de este estudio es reexaminar de primera mano una muestra representativa de la evidencia que soporta tales interpretaciones, para caracterizarla desde protocolos de análisis alternativos. Con ello se pretende recabar observaciones alternativas sobre el ciclo formativo de este lugar (Jiménez Jáimez 2008). Así pues, ¿es posible aportar algo nuevo sobre la formación de El Ventorro estudiando una selección del material cerámico encontrado en 1981 ?

\section{Metodología de estudio}

Este artículo se centra en explotar el potencial informativo de la cerámica prehistórica sobre las dinámicas a que ha estado sometida desde que fue descartada y hasta llegar a manos del arqueólogo (Orton et al. 1997: 241-244). Se ha objetado que tal asunto "es el resultado de un infinito número de acciones y reutilizaciones difícilmente accesibles en términos "positivos" a un análisis arqueológico" (Díaz-del-Río 2001: 248). Sin embargo, existen vías de avance, aún poco exploradas. La cerámica antes de cocer es un material muy maleable; tras su cocción adquiere suficiente tenacidad como para permitir reconocer ciertas trazas tecnológicas (p.e. García Rosselló y Calvo Trías 2013) y huellas de uso (p.e. Skibo 1992: 42-49), pero también ofrece pistas sobre los avatares experimentados ya en estado fragmentario (Garrow et al. 2005; Brudenell y Cooper 2008; Edwards 2009, 2012; Beadsmoore et al. 2010; Wolfram 2013). Para aproximarnos a tal aspecto hemos diseñado un protocolo de análisis inspirado en el método tafonómico aplicado a los huesos (p.e. Yravedra Sainz de los Terreros 2013) y dirigido a identificar las dinámicas de fragmentación de la cerámica, y evaluar sus tasas de representación y estado de deterioro (cf. Sánchez-Polo y Blanco-González 2014: 14-17). Además se ha efectuado un intento exhaustivo para concertar o casar fragmentos entre sí. Con todo ello se pretende aclarar cuestiones sobre la composición, procedencia, temporalidad y grado de intencionalidad de los depósitos: la presencia o dispersión y pérdida de piezas de un mismo recipiente; las trayectorias experimentadas por los trozos tras su rotura y el lapso transcurrido; el tipo de afecciones sufridas; comprobar si partes de una misma vasija acabaron en distintos contextos -lo que apuntaría a su posible relleno simultáneo-o si existen patrones de representación de restos difícilmente aleatorios.

Se ha seleccionado la campaña de 1981 en El Ventorro (Fig. 2) por afectar de lleno a una serie de contextos deposicionales de interpretación dispar (Priego y Quero 1992: 83-125; Díaz-del-Río 2001: 243-245). Además, por el volumen y naturaleza de sus restos, la cabaña 013 es sin duda extraordinaria incluso a escala peninsular (Díaz-del-Río 2001: 245-246, nota 110) y merece una reevaluación más rigurosa. Dado que la colección cerámica recuperada en esa cata de $128 \mathrm{~m}^{2}$ es desmesurada -33.595 fragmentos sólo en la cabaña 013hubo que seleccionar una muestra abarcable y representativa. Los fragmentos informes de galbo fueron desechados porque para el análisis aquí perseguido consumen excesivo tiempo frente a la 


\begin{tabular}{|c|c|c|c|}
\hline Categoría & Superficie & Celda A & Celda B \\
\hline 1 & $<6.25 \mathrm{~cm}^{2}$ & $2.5 \times 2.5 \mathrm{~cm}$ & \\
\hline 2 & $6.25-12.5 \mathrm{~cm}^{2}$ & $3.5 \times 3.5 \mathrm{~cm}$ & $3 \times 4.5 \mathrm{~cm}$ \\
\hline 3 & $12.5-66.5 \mathrm{~cm}^{2}$ & $8.2 \times 8.2 \mathrm{~cm}$ & $7 \times 9.5 \mathrm{~cm}$ \\
\hline 4 & $>66.5 \mathrm{~cm}^{2}$ & & \\
\hline
\end{tabular}

Tabla 1.- Categorías de tamaño de los fragmentos cerámicos según su superficie $\left(\mathrm{en} \mathrm{cm}^{2}\right)$.

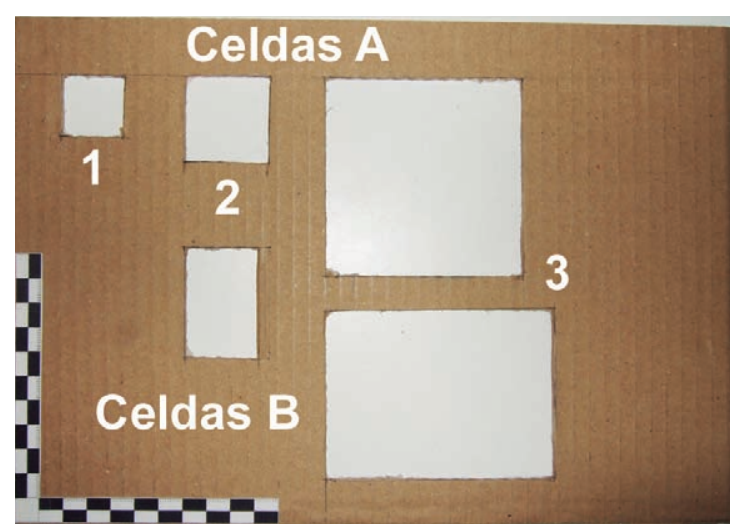

Figura 3.- Plantilla de cartón para clasificar la cerámica por tamaños.

\begin{tabular}{|c|c|c|c|}
\hline Grado & Condición & $\begin{array}{c}\text { Fracturas } \\
\text { y esquinas }\end{array}$ & Superficies \\
\hline 1 & $\begin{array}{c}\text { No } \\
\text { erosionado }\end{array}$ & $\begin{array}{c}\text { Aspecto } \\
\text { cortante, } \\
\text { anguloso }\end{array}$ & $\begin{array}{c}\text { Bien } \\
\text { conservadas por } \\
\text { ambas caras }\end{array}$ \\
\hline 2 & $\begin{array}{c}\text { Erosión } \\
\text { puntual }\end{array}$ & $\begin{array}{c}\text { Aspecto } \\
\text { fresco o } \\
\text { afeción } \\
\text { local }\end{array}$ & $\begin{array}{c}\text { Una única } \\
\text { cara afectada } \\
\text { puntualmente }\end{array}$ \\
\hline 3 & $\begin{array}{c}\text { Erosión } \\
\text { intensa }\end{array}$ & $\begin{array}{c}\text { Aspecto } \\
\text { levemente } \\
\text { rodado }\end{array}$ & $\begin{array}{c}\text { Ambas caras } \\
\text { afectadas } \\
\text { levemente }\end{array}$ \\
\hline 4 & $\begin{array}{c}\text { Muy } \\
\text { erosionado }\end{array}$ & $\begin{array}{c}\text { Redon- } \\
\text { deadas, } \\
\text { biseladas }\end{array}$ & $\begin{array}{c}\text { Pérdida } \\
\text { sustancial } \\
\text { afloración del } \\
\text { núcleo }\end{array}$ \\
\hline
\end{tabular}

Tabla 2.- Categorías para la variable abrasión. información que pueden aportar (Bollong 1994: 16-17; Orton et al. 1997: 239-240). Así pues, nuestros esfuerzos se centraron exclusivamente en el material selecto, es decir, decorado o con forma reconocible -bordes, carenas, fondos, etc.recuperado dentro de los Fondos 008, 009, 010, 011 y 012 y en los cuadros B-1, C-1, D-1 y D-2, correspondientes al área de la cabaña 013 (Fig. 2).

La elección de los atributos considerados en nuestro examen requiere una breve explicación. El recuento de fragmentos o número de restos (NR) es una variable comúnmente empleada para describir colecciones cerámicas (p.e. Priego y Quero 1992: 208; Carmona Ballestero 2013: 119-124). Sin embargo, depende demasiado de las propiedades mecánicas de la cerámica y sus patrones de rotura, por lo que no se considera un indicador fiable de la frecuencia relativa (Solheim 1960: 325; Chase 1985: 218; Byrd y Owens Jr 1997: 315; Orton et al. 1997: 189-194). La combinación de atributos, como el NR y el peso (p.e. Díaz-del-Río et al. 1997, Tabla 2; Díaz-del-Río y Vicent García 2006: 27, fig. 2; Edwards 2009: 139-141), resulta un método mucho más robusto para caracterizar un conjunto cerámico. Para nuestro propósito, la superficie y el peso de los fragmentos son los atributos que mejor definen su talla (e.g. Solheim 1960; Chase 1985: 218; Byrd y Owens Jr 1997: 315-316; Orton et al. 1997: 191-194). Debemos añadir que cada colección presenta un rango de variabilidad distintivo, al que debe adecuarse su clasificación. El subconjunto de piezas selectas de El Ventorro ha sido sometido a una estrategia de medición sistemática para recabar datos cuantitativos sobre dos atributos: a) su tamaño, una variable de escala con nivel de medida de intervalo, y b) su erosión, una variable categórica con nivel ordinal de medida. Respecto al tamaño (p.e. Díaz-del-Río 2001: 189, fig. 35; 234, fig. 57), tras la observación preliminar de la casuística que presentaba la muestra madrileña se optó por emplear cuatro categorías con unos umbrales predefinidos (tabla 1). La magnitud a medir fue la superficie de las piezas, expresada en $\mathrm{cm}^{2}$ (Chase 1985: 218; Byrd y Owens Jr 1997: 317). Una plantilla de cartón con vanos recortados permitió clasificar la cerámica de forma ágil y precisa (Fig. 3). Atendiendo a los diferentes patrones de rotura de los trozos, se contemplaron dos formatos alternativos para cada tamaño: una celda cuadrangular (Tabla 1, celda A) y otra oblonga (Tabla 1, celda B), ambas representando la misma superficie. La categoría 1 se atribuyó a aquellos trozos que cupieran por la celda menor $\left(6,25 \mathrm{~cm}^{2}\right)$; la categoría 2 a aquellos que pasaran por el vano mediano $\left(12,5 \mathrm{~cm}^{2}\right)$ pero no por el menor; la categoría 3 a los que pasaran 
por la celda mayor $\left(66,5 \mathrm{~cm}^{2}\right)$ pero no por la mediana y la categoría 4 a los que no pasaran por la celda mayor (Fig. 3). Además se anotó el peso expresado en gr, empleando una pequeña báscula eléctrica de precisión.

Se ha subrayado la importancia del ciclo de uso y descarte de los restos arqueológicos en la configuración final de los mismos (Jiménez Jáimez 2008). Dicho aspecto debería considerarse un requisito ineludible previo a cualquier interpretación espacial y funcional (Blanco González, e.p.). El grado de conservación de la cerámica es una variable muy informativa en tal sentido (p.e. Bradley y Fulford 1980; Allen 1989; Schiffer y Skibo 1989; Sørensen 1996: 67-70; Buko 1998, 399-403; Edwards 2009: 147-159, 2012: 86-89; Beadsmoore et al. 2010, 125-9; Wolfram 2013, 82-6, tab. 1) hasta ahora desatendida en España. Los principios básicos de este enfoque son que la condición actual de los fragmentos ofrece información sobre los procesos a que han estado sometidos (Schiffer y Skibo 1989: 101) y que es posible diferenciar entre las afecciones prey posdeposicionales (Bradley y Fulford 1980: 90). La resistencia ante tales alteraciones dependerá de la tenacidad de la pasta y acabados cerámicos y de la naturaleza e intensidad de la abrasión (Sørensen 1996: 67; Buko 1998: 402). Siempre puede haber excepciones, pero las colecciones cerámicas suelen presentar propiedades físicas homogéneas y por tanto pueden ser evaluadas con unos criterios relativos. No existe un método consensuado para medir la erosión en los fragmentos cerámicos. Sørensen (1996: 67) propuso tres categorías de abrasión -baja, media e intensa- reconocibles en un mismo fragmento (Sørensen 1996: 65, fig. 41). Por su parte, Buko (1998: 400, fig. 13) y Edwards (2009: 148, 2012: 88, fig. 7.11) plantearon una clasificación cuádruple y homogénea para cada fragmento. La escala ordinal aquí empleada (tabla 2) se basa en estos últimos autores; tiene como unidad de análisis cada fragmento y contempla cuatro categorías definidas por el grado de afección sobre las superficies y cantos de cada pieza. Un ejemplo de cada tipo de erosión puede verse en la Fig. 4.

Por último se cotejaron unos fragmentos con otros para comprobar si concertaban entre sí o si pudieran atribuirse visualmente -por sus propiedades- a un mismo recipiente. Para ello se siguieron las estrategias de estudio y registro empleadas con éxito en el ámbito anglosajón (Bollong 1994; Sørensen 1996; Garrow et al. 2005; Beadsmoore et al. 2010; Garrow 2010; Edwards 2009, 2012). Este procedimiento se repitió sistemáticamente entre piezas del mismo contexto y distintos niveles y entre trozos de distintos contextos. Ello permitió reconocer diversas "conexiones" entre fragmentos (Orton et al. 1997: 236-243) muchas de ellas sin remontaje directo, por lo que se empleó una plantilla con una serie de atributos que permite expresar tales asociaciones como porcentajes de probabilidad de acierto (Blanco González y Chapman 2014).

Las tareas mencionadas exigieron extender toda la cerámica a estudiar de cada contexto - las cinco fosas y la cabaña 013- en zonas independientes, sobre grandes tablones o en el suelo de las dos dependencias habilitadas en el Museo de San Isidro (Fig. 5). Además de referir su contexto deposicional -"fondos" o "cabaña"- los materiales estaban guardados por cuadrículas (Fig. 2), por alzadas y a partir del nivel 4 en adelante a menudo también por el cuadrante en que se hallaron dentro del cuadro. Para evitar confusiones o pérdidas de tales referencias contextuales, las cerámicas se agruparon por bolsas con sus respectivas etiquetas, y cada conjunto se delimitó con cinta adhesiva (Fig. 5). Se contó con tres personas durante 15 jornadas, dedicando unas 100 horas de trabajo efectivas. Los atributos de superficie, peso y erosión de todos los trozos se cumplimentaron en una base de datos. Además se anotó y asignó un número correlativo a cada caso de conexión entre piezas, tanto si casaban directamente - muchas ya pegadas- como si se sospecha su correspondencia a un mismo recipiente (Bollong 1994; Blanco González y Chapman 2014).

\section{Caracterización de la muestra cerámica}

De 36.578 fragmentos cerámicos recuperados en la cata de 1981 (Priego y Quero 1992: 90-110) se han estudiado 3.837 piezas, que representan el $10,5 \%$ del total (tabla 3 ). La mayor parte de los fragmentos -3.296 - pertenecen a la cabaña 013, y representan el $10 \%$ de las piezas halladas en ese contexto deposicional, mientras que de las fosas anexas se ha analizado entre el $9 \%$ y el $20,5 \%$ de sus contenidos cerámicos (tabla 3). En los siguientes párrafos se prescinde de la referencia a los niveles artificiales de $10 \mathrm{~cm}$ (Priego y Quero 1992: 83), pues con seguridad mezclaron restos contenidos en sedimentos distintos (Díaz-del-Río 2001: 245).

El $84 \%$ del total de los fragmentos estudiados son de tamaño mediano o grande (grupos 2 y 3 ) (tabla 1), seguidos del tamaño pequeño (grupo 1) con el $13 \%$, siendo testimoniales los fragmentos mayores de $66.5 \mathrm{~cm}^{2}$ (grupo 4) con apenas un $3 \%$ de los casos (tabla 4). La mayor parte de los 

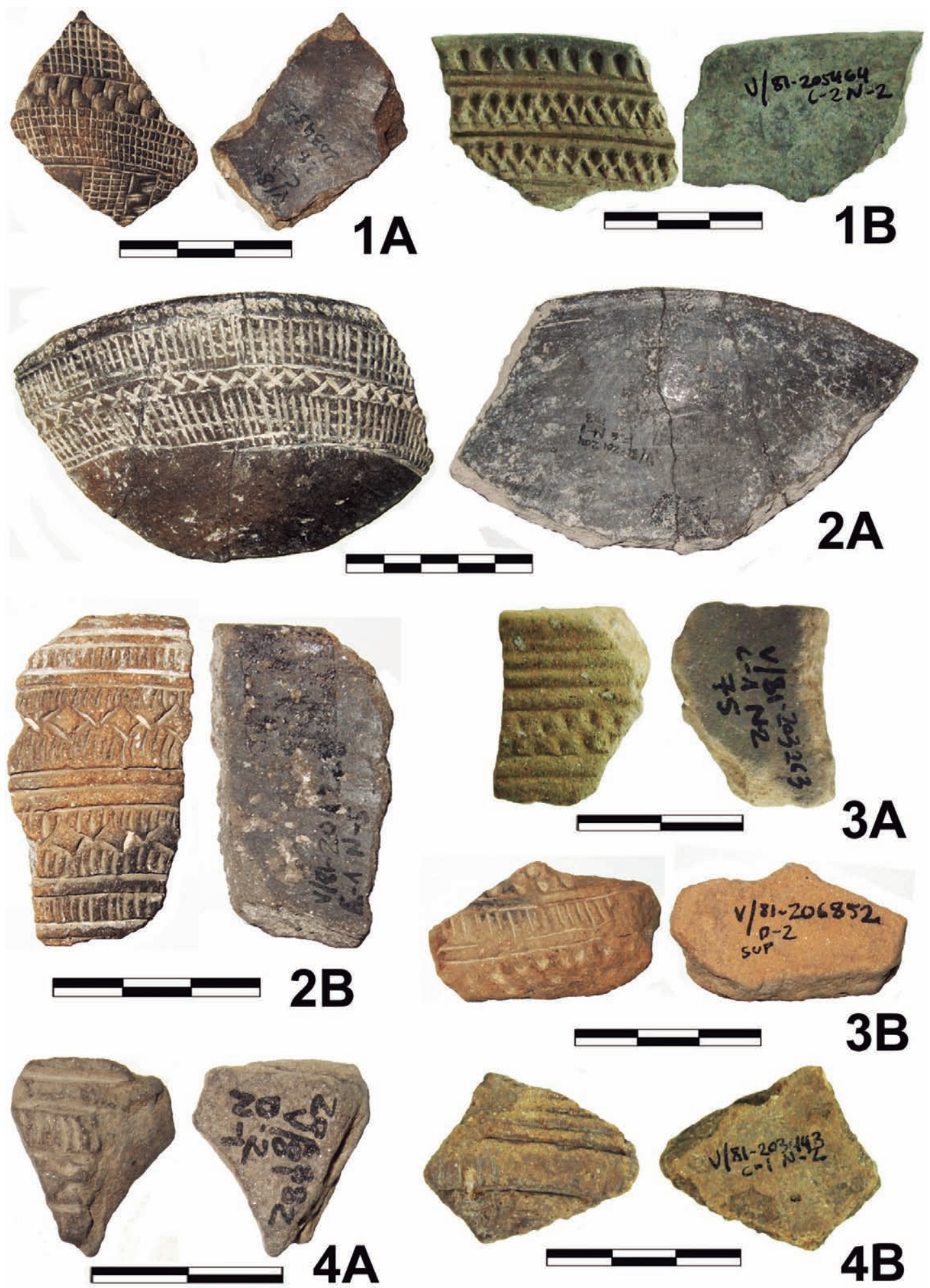

Figura 4.- Ejemplos de fragmentos campaniformes para cada categoría de abrasión: Grado 1, no erosionado (1,A y 1,B); Grado 2, erosión puntual (2,A y 2, B); Grado 3, erosión leve pero generalizada (3,A y 3,B) y Grado 4, muy erosionado $(4, \mathrm{~A}$ y $4, \mathrm{~B})$. 


\begin{tabular}{|l|c|c|c|l|l|l|}
\hline \multicolumn{1}{|c|}{ Contexto } & NR total & NR est. & Peso est. (gr) & NR camp. & Est./contexto & Est./1981 \\
\hline Fondo 008 & 841 & 153 & 4280 & & $18 \%$ & $0,41 \%$ \\
\hline Fondo 009 & 166 & 15 & 535 & & $9 \%$ & $0,04 \%$ \\
\hline Fondo 010 & 379 & 60 & 2047 & & $16 \%$ & $0,16 \%$ \\
\hline Fondo 011 & 776 & 144 & 4952 & 5 & $18,50 \%$ & $0,39 \%$ \\
\hline Fondo 012 & 821 & 169 & 4331 & & $20,50 \%$ & $0,46 \%$ \\
\hline Cabaña 013 & 33595 & 3296 & 61251 & 106 & $10 \%$ & $9,01 \%$ \\
\hline Total 1981 & 36578 & 3837 & 77396 & 111 & & $10,50 \%$ \\
\hline
\end{tabular}

Tabla 3.- Frecuencia y proporción del material cerámico. NR total = número de restos total; NR est. = estudiados; Peso est. $=$ peso de la muestra estudiada $($ en gramos $) ; \mathrm{NR}$ camp. $=$ campaniformes; Est./cont. $=$ porcentaje restos estudiados por contexto; Est./1981 = porcentaje restos estudiados por NR total.

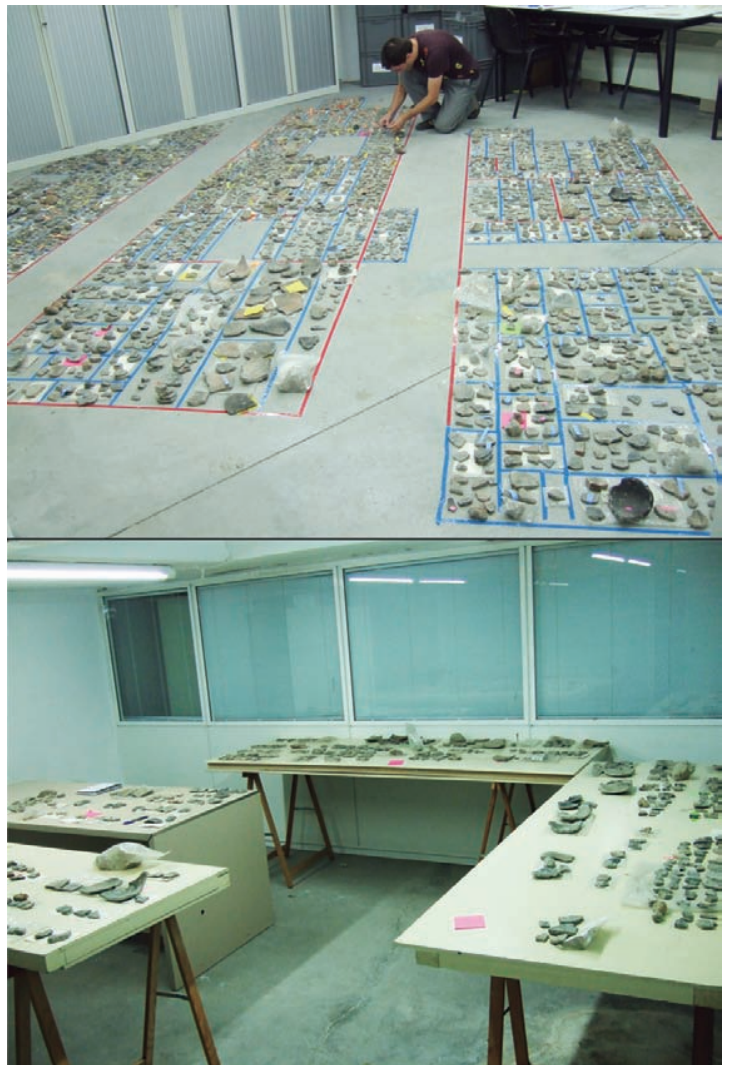

Figura 5.- Trabajo en curso en los laboratorios habilitados en el Museo de San Isidro (Madrid) para estudiar el material selecto de El Ventorro 1981.

pedazos más grandes -con una trayectoria breve entre su rotura y deposición- se recuperaron en la cabaña 013, pero en proporción también aparecen en las fosas (Fig. 6). Respecto al nivel de erosión (tabla 2) predomina la cerámica bien conservada (grado 1) con un $60 \%$ de la muestra estudiada,

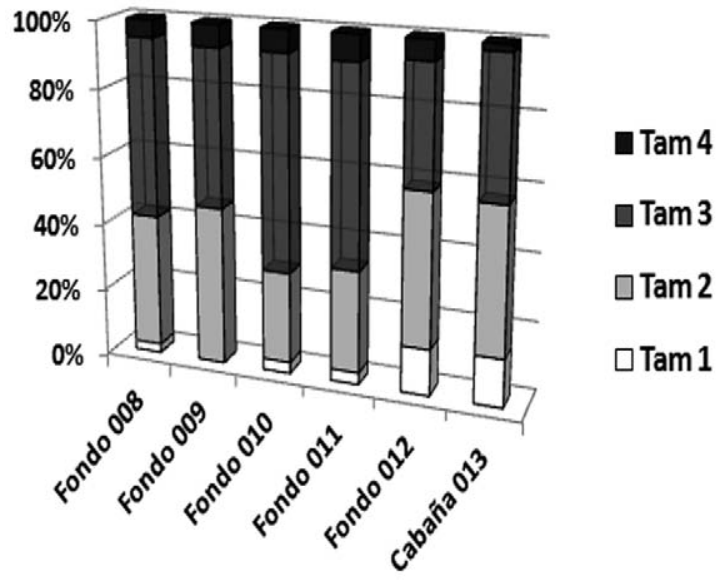

Figura 6.- Gráfico de porcentajes acumulados con los valores de tamaño por contextos.

mientras que un tercio del total exhibe afecciones puntuales (grado 2) y los trozos más intensamente erosionados (grados 3 y 4) representan sólo el 7\% (tabla 4). Las fosas contienen mayoritariamente cerámicas de fracturas frescas (grado 1), con una débil presencia de trozos clasificados en el grado 2 y casi total ausencia de los más desgastados (grados 3 y 4) (tabla 4 y Fig. 7). El material puntualmente rodado (grado 2) y el más intensamente erosionado (grados 3 y 4) está mejor representado en la cabaña 013 (Fig. 7). La prueba $\mathrm{H}$ de Kruskal-Wallis permitió descartar que tales diferencias entre los valores de tamaño $\left(\chi^{2}=5,0\right.$ y $\left.\mathrm{p}=0,416\right)$ y erosión $\left(\chi^{2}=3,143\right.$ y $\mathrm{p}$ $=0,370)$ fueran estadísticamente significativas. Es decir, que las muestras cerámicas estudiadas no son lo suficientemente desiguales para afirmar que proceden de distintas poblaciones; parecen ser conjuntos sujetos a los mismos procesos de fragmentación y rodamiento. 


\begin{tabular}{|l|l|l|l|l|l|l|l|l|l|}
\hline Contexto & NR est. & Tam 1 & Tam 2 & Tam 3 & Tam 4 & Abr Gr1 & Abr Gr2 & Abr Gr3 & Abr G4 \\
\hline Fondo 008 & 153 & 4 & 60 & 81 & 8 & 153 & 0 & 0 & 0 \\
\hline Fondo 009 & 15 & 0 & 7 & 7 & 1 & 15 & 0 & 0 & 0 \\
\hline Fondo 010 & 60 & 2 & 16 & 38 & 4 & 59 & 1 & 0 & 0 \\
\hline Fondo 011 & 144 & 5 & 43 & 85 & 11 & 142 & 2 & 0 & 0 \\
\hline Fondo 012 & 169 & 23 & 76 & 60 & 10 & 166 & 2 & 1 & 0 \\
\hline $\begin{array}{l}\text { Cabaña } \\
\text { 013 }\end{array}$ & 3296 & 465 & 1422 & 1343 & 66 & 1784 & 1252 & 222 & 38 \\
\hline $\begin{array}{l}\text { Total } \\
\text { muestra }\end{array}$ & 3837 & 499 & 1624 & 1614 & 100 & 2319 & 1257 & 223 & 38 \\
\hline$\%$ muestra & & $13 \%$ & $42 \%$ & $42 \%$ & $3 \%$ & $60 \%$ & $33 \%$ & $6 \%$ & $1 \%$ \\
\hline
\end{tabular}

Tabla 4.- Cantidad (NR), tamaño y abrasión de la cerámica estudiada, por contextos deposicionales. Tam = Tamaño (categorías 1-4). Abr= Abrasión (grados 1-4).

\begin{tabular}{|l|c|c|c|c|c|}
\hline & Tamaño 1 & Tamaño 2 & Tamaño 3 & Tamaño 4 & TOTAL \\
\hline Abrasión 1 & 295 & 968 & 972 & 86 & 2319 \\
\hline Abrasión 2 & 166 & 546 & 534 & 10 & 1257 \\
\hline Abrasión 3 & 35 & 98 & 87 & 2 & 223 \\
\hline Abrasión 4 & 3 & 12 & 21 & 2 & 38 \\
\hline TOTAL & 499 & 1624 & 1614 & 100 & 3837 \\
\hline
\end{tabular}

Tabla 5.- Relación entre las variables de tamaño y abrasión cerámica.

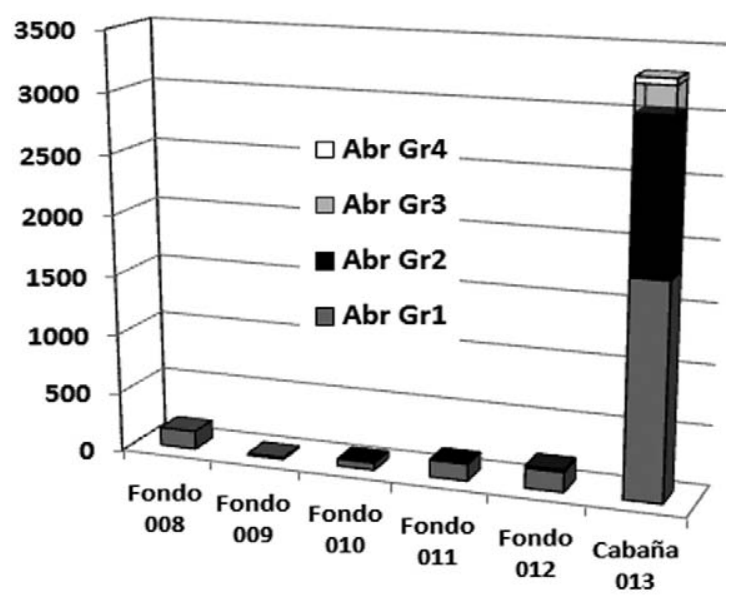

Figura 7.- Gráfico de barras con las frecuencias de abrasión cerámica por contextos.
Se ha afirmado que los restos cerámicos con dilatadas trayectorias de alteración tienden a hacerse más pequeños (Bradley y Fulford 1980: 86). Así pues, la posible asociación entre el tamaño de los fragmentos y su abrasión (tabla 5) ha sido evaluada mediante el test de Kendall B-Tau (Edwards 2009: 355-358, 2012: 88-89), ofreciendo un resultado negativo cercano a $0(\tau=-0,032$ y p $=0,033)$. Esto significa que se trata de variables no relacionadas, es decir, que los fragmentos más pequeños no son los peor conservados, y por tanto ambas dinámicas degradativas fueron independientes

El ejercicio de remontaje (tabla 6) ha permitido reconocer 310 conexiones entre 730 fragmentos, implicando entre 2 y 11 trozos por asociación; 39 de esos casos conciertan físicamente y el resto son atribuciones posibles al mismo recipiente, con porcentajes medio-altos (75-90\%) de probabilidad de acierto (Blanco González y Chapman 2014). El 96\% de esas conexiones vinculan piezas del mismo contexto -la gran mayoría dentro de la cabaña 013- y también se han identificado conexiones 
entre los fondos 010,011 y 012 y la cabaña 013 , pero no entre unas fosas con otras (tabla 6). Es importante señalar que 3.107 trozos, el $81 \%$ de la muestra cerámica, son "fragmentos huérfanos" sin remontaje local (Schiffer 1987: 298-302; Bollong 1994: 18, Tabla 1; Chapman y Gaydarska 2007: 81) y que trozos que casan entre sí presentan pátinas, tipos de atrición e incluso coloraciones distintas, indicativas de afecciones divergentes adquiridas tras su rotura (Fig. 8).

Por último, ciertos materiales ${ }^{2}$ merecen un comentario individualizado. Así, se han reconocido fragmentos reutilizados, con los cantos redondeados por fricción contra una superficie abrasiva y que podrían haberse empleado como fichas o tapas (?) (Fig. 8). También se identificó una docena de piezas que por su decoración y avanzado desgaste son de plausible datación neolítica (Fig. 9), dos de ellas procedentes del fondo 011 y el resto de la cabaña 013. Los 111 fragmentos campaniformes hallados en el fondo 011 y la cabaña 013 (tabla 3) presentan cierta variabilidad tafonómica: el $66 \%$ es de pequeña o mediana talla (grupos 1 y 2 ) y el restante $34 \%$ es mayor de $12,5 \mathrm{~cm}^{2}$ (grupos 3 y 4 ) y frente al $74 \%$ bien conservados (grado 1) el 23\% están algo rodados (grado 2) (Fig. 4). Sabemos que su erosión y tamaño no están correlacionados y se deben a dinámicas autónomas. La prueba de $\chi^{2}$ nos ha permitido cotejar ambas variables del subconjunto de cerámicas campaniformes frente al resto de la muestra, para saber si sus diferencias eran reales. El resultado $\left(\chi^{2}=56,0\right.$ y $\left.\mathrm{p}=0,229\right)$ señala que los campaniformes no experimentaron afecciones distintivas. Así pues, todas las cerámicas, con independencia de su decoración, compartieron similares avatares y alteraciones posrotura antes de incorporarse a los socavones, lo cual es una observación sin duda interesante.

\section{Discusión}

La lectura espacial y funcional defendida por los excavadores de la cata de 1981 en El Ventorro pivota sobre la idea central de estar ante una vivienda y sus dependencias accesorias (Priego y Quero 1992). Así pues, resulta crucial escrutar la génesis de la cabaña 013. Hoy día existen numerosos ejemplos de cabañas calcolíticas en la Meseta. La discusión sobre su carácter doméstico está aprisionada por el lenguaje; el acto de nombrarlas condiciona y constriñe su interpretación arqueológica (Hodder 1999: 9495). Son estructuras muy variables en tamaño -entre 5 y $50 \mathrm{~m}^{2}-$ y solución arquitectónica - cubetas rehundidas, con zanja perimetral, con pies derechos, con zócalo de mampostería, etc.-, aunque siempre se cita como denominador común su cubrición con elementos perecederos (p.e. Díaz-del-Río 2001: 220-227; García Barrios 2004-2005; Rodríguez Marcos 2005; Fabián García 2006: 389-391; Carmona Ballestero 2013: 208, Tabla 36; Liesau et al. 2013: 141). De todas esas fórmulas, la que interesa aquí es la de "fondo de cabaña". Su interpretación como viviendas semihipogeas ha sido convincentemente rebatida para el Calcolítico andaluz (Jiménez Jáimez y Márquez Romero 2006; Jiménez Jáimez 2007) y gran parte de esos argumentos son aplicables a la cabaña 013 de El Ventorro. Sus ínfimos requisitos tecnológicos y limitadas condiciones de habitabilidad, la irregularidad de su planta, la escasa verticalidad de sus paredes y la ausencia de hoyos de poste exteriores desacreditan las analogías con auténticas pithouses etnográficas (contra Priego y Quero 1992: 357 y 363, fig. 192). Fuera de la cubeta subterránea - "vivienda inferior"cuesta reconocer un espacio interior frente al exterior de la vivienda: el suelo de la "vivienda superior" - la cabaña mejor documentada del yacimiento- carece de "planta definida" (Priego y Quero 1992: 102) y consiste en un delgado lecho expandido horizontalmente, es decir, sin barreras -tabiques- que lo contuvieran. Su proceso de colmatado como sucesivos solados internos de sendas viviendas superpuestas no es verosímil. El espesor de tales niveles o su densidad de restos no pueden relacionarse con la intensidad y duración de las ocupaciones (contra Priego y Quero 1992: 118), sino con el tipo de material constructivo, las tasas de deposición o vertido y los consiguientes procesos de compactación y reducción (Díaz-delRío 2001: 120-123; Jiménez Jáimez 2008: 130132). La morfología buzante de los lentejones o las acumulaciones cónicas de material (Priego y Quero 1992: 101 y 103) son incompatibles con verdaderos suelos de ocupación, por definición horizontales (Jiménez Jáimez 2007: 482-485).

Los restos estructurales -suelos, hogares, áreas de actividad- del interior de la cabaña 013 también suscitan dudas (Díaz-del-Río 2001: 246). Una mayor atención a cómo llegaron hasta allí los materiales, mediante su revisión directa, se consideraba crucial para comprender la génesis de este contexto (Díaz-del-Río 2001: 248). La presencia de solados no se concilia con la identificación de trozos cerámicos que casan entre el nivel 3 y el nivel 9, es decir, entre las dos pretendidas viviendas superpuestas (tabla 6), o con la afirmación de que "el estrato superior se interpenetra con el inferior en su zona central" 

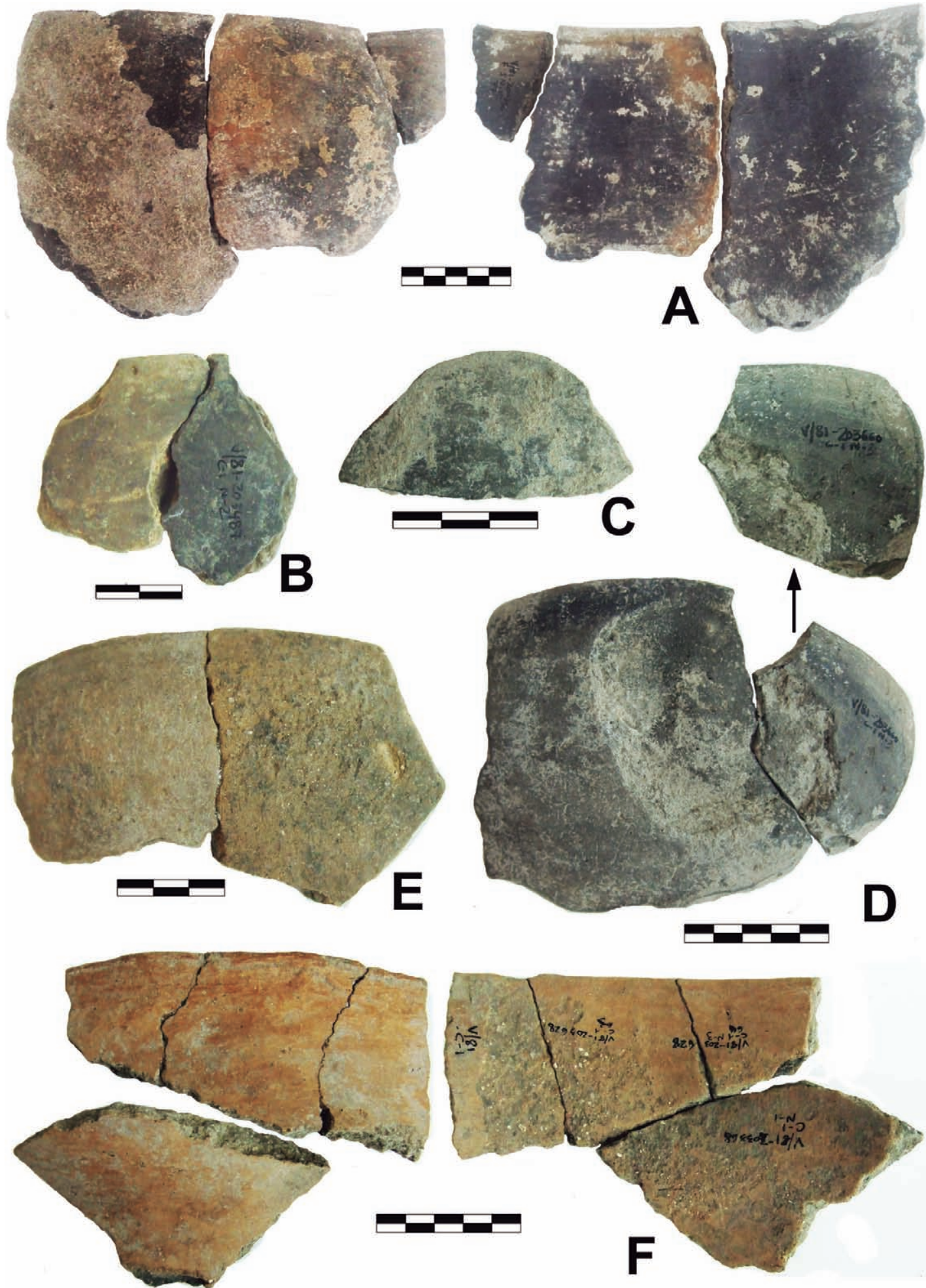

Figura 8.- Conexiones y afecciones. A. Trozos que casan y presentan distinta coloración posrotura. B. Fragmentos concertantes con pérdida de materia en la fractura y distinta tonalidad. C. Pieza con canto pulido, reutilizada. D. Dos trozos que casan, con desconchado prerrotura y reutilización del trozo menor, pulido. E. Remontaje entre piezas con distinto desgaste. F. Erosión de grado 2 previa a la rotura. 


\begin{tabular}{|l|c|c|c|c|c|c|}
\hline & F 008 & F 009 & F 010 & F 011 & F 012 & Cab 013 \\
\hline F 008 & $6+\underline{\mathbf{4}}$ & & & & & \\
\hline F 009 & & 2 & & & & \\
\hline F 010 & & & $\underline{4}$ & & & 1 \\
\hline F 011 & & & & $7+\underline{\mathbf{3}}$ & & 3 \\
\hline F 012 & & & & & $3+\underline{\mathbf{1}}$ & $6+\underline{\mathbf{1}}$ \\
\hline Cab 013 & & & & & & $244+\underline{\mathbf{2 6}}$ \\
\hline
\end{tabular}

Tabla 6.- Remontajes entre fragmentos cerámicos. Los números en negrita y subrayados indican conexiones seguras (trozos que casan), el resto son posibles correspondencias al mismo recipiente.
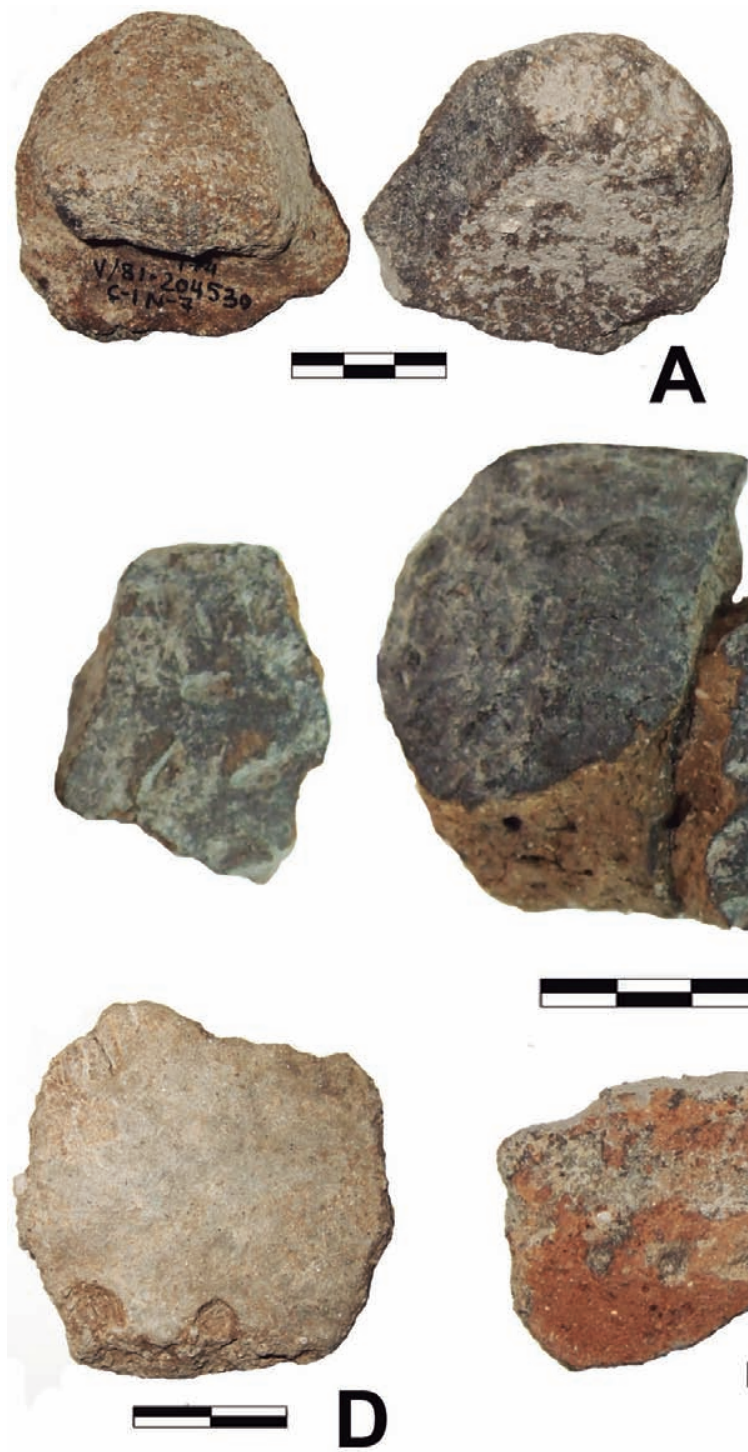
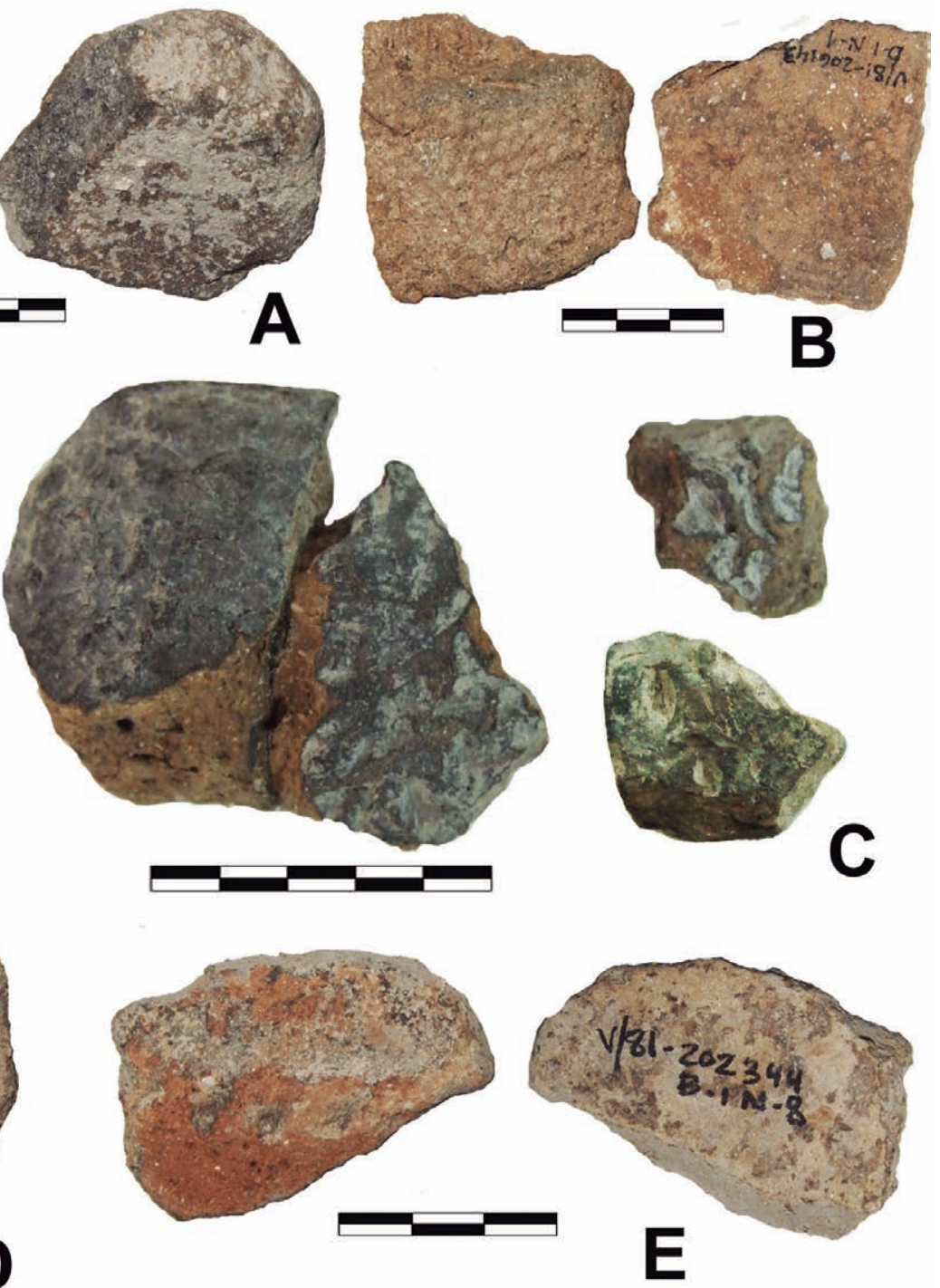

Figura 9.- Fragmentos cerámicos de probable atribución neolítica, intensamente rodados. 
(Priego y Quero 1992: 102; cf. Díaz-del-Río 2001: 245). Los fragmentos del supuesto encachado de acceso de la "cabaña superior", en el nivel 3 del cuadro B-2 (Priego y Quero 1992: 103-104 y 123, Lám. XX, 2) no han sufrido las roturas esperables tras su continuo pisoteo - predomina el tamaño 3y sus superficies frescas (grados 1 y 2) no cuadran con el desgaste por fricción previsible en una zona de tránsito como la entrada. El hogar de la "vivienda inferior" (Priego y Quero 1992: 105 y 124, Lám. XXI, 1) carece del cuidado diseño habitual (p.e. Fabián García 2006: 391), y podría tratarse de un agregado de materiales redepositados: piedras quemadas, cenizas y trozos de dos cuencos muy incompletos. Las concentraciones de restos líticos en las "cabañas inferior» y "superior" coinciden en la cuadrícula B-1 (Priego y Quero 1992: 104-105), lo que tal vez concuerde mejor con un vertido voluminoso de despojos de talla en lugar de sendos talleres de sílex. Así pues tales estructuras y los restos cerámicos y líticos, las pellas de barro, los molinos y la fauna se compadecen mejor con la idea de unos residuos secundarios erráticos, desplazados de su contexto originario.

Los excavadores de la cabaña 013 creen estar ante "una vivienda permanente, cuyo suelo se preparaba y limpiaba, arrojando los residuos originados por la actividad cotidiana en los basureros cercanos" (Priego y Quero 1992: 118). Sin embargo, el $86 \%$ de las cerámicas estudiadas de este contexto son mayores de $6,25 \mathrm{~cm}^{2}$ (tamaños 2 a 4) (tabla 4 y Fig. 6), y no pueden considerarse microdesechos que escaparan fácilmente al barrido (Jiménez Jáimez 2008: 129-130). Al igual que en las catas próximas (Priego y Quero 1992: 47; Díazdel-Río 2001: 239, nota 105), hemos reconocido conexiones entre cerámicas de las fosas y de la cabaña 13 (tabla 6) que vinculan su relleno. Dentro de los pozos su conservación es óptima - predomina el grado 1-(tabla 4 y Fig. 7), lo cual cuadraría con un vertido rápido de aquellas vasijas rotas en las inmediaciones. El $27,5 \%$ de fragmentos -1.058 , de los que 248 presentan conexión con otros- de todos los contextos son de tamaño mediano-grande (grupos 3 y 4) y aspecto fresco (grado 1) (tabla 4). Se trata de cuencos y ollas que pudieron emplearse en episodios repetidos de consumo, tal vez en festines tal como propone Díaz-del-Río (2001: 249), descartados inmediatamente tras su rotura. Con los argumentos aquí manejados su carácter rutinario y doméstico u ocasional y extraordinario no puede discernirse. Tales restos comparecen en las fosas y la cabaña 013 a cualquier profundidad, por lo cual su descarte y el relleno de las cubetas estuvo relacionado de alguna forma. Por otra parte el número de "fragmentos huérfanos" sigue siendo abrumador; sólo una porción minoritaria de tales enseres acabó en los hoyos.

Díaz-del-Río (2001: 248-249) supone que el relleno de la cabaña 013 fue relativamente rápido porque no hay "indicio alguno de haber sufrido un largo proceso previo a su deposición definitiva". No tenemos información directa sobre la tasa de sedimentación seguida en este contexto deposicional, pero se atisba una mezcla de cerámicas heterogéneas, en su mayoría lisas, pero incluyendo 10 piezas neolíticas (Fig. 9) y 106 campaniformes (Fig. 4). No toda la cerámica allí incorporada acababa de romperse. Algunas permanecieron abandonadas al aire libre por un tiempo, sufriendo desgaste puntual por meteorización en una sola cara antes de romperse en más pedazos (Fig. 8F). Hay ejemplos de afecciones prerrotura, como desconchones, probablemente debidos a contrastes térmicos (Fig. 8D) y ciertos fragmentos pulidos para ser reutilizados (Fig. 8C y D) informan de prácticas de manipulación y reciclado de trozos desechados. Las huellas tafonómicas indican que el $46 \%$ de los pedazos exhibe algún grado de rodamiento (grados 2 a 4) (tabla 4). Además se han encontrado trozos que conciertan entre sí pero presentan diferentes afecciones posrotura como cambios de color por exposición al fuego, pérdida de materia en las roturas o desgates distintos (Fig. 8A, B y E). Priego y Quero (1992: 104) ya señalaron que partes de unos mismos recipientes campaniformes "se han podido pegar a pesar de tener distinto grado de erosión y superficies de distinta coloración". En la cabaña 2 de Camino de las Yeseras (San Fernando de Henares, Madrid) un $41 \%$ de la cerámica selecta es campaniforme, y su rodamiento hace pensar que fue extraída de tumbas y acopiada en aquel ámbito (Liesau et al. 2013: 143 y 147). Lo cierto es que en contextos deposicionales estables, como las tumbas, la cerámica no se degrada mecánicamente por erosión (Bradley y Fulford 1980: 90; Edwards 2012: 89). En cualquier caso, los trozos campaniformes estaban desgastados y el dato es importante, pues algo similar se observa en El Ventorro, donde el 25\% de los hallados en 1981 están algo rodados (grado 2) y el $67 \%$ son pequeños o medianos (grupos 1 y 2). Todos esos restos se sometieron a unos mismos procesos degradativos, apilados al aire libre sin sufrir pisoteo ni nuevas roturas, en contextos donde experimentaron meteorización y desgaste (tablas 4 y 5) antes de ser enterrados definitivamente. Así pues, en este estadio de su trayectoria o biografía cultural los campaniformes no parecen haber recibido ningún trato especial. Respecto a los materiales neolíticos, ya se había previsto su identificación al revisarse 
conjuntos de épocas posteriores (Díaz-del-Río 2001: 170, nota 52). Su carácter residual y su incorporación involuntaria -incluso inadvertidaa tales contextos no debe sorprender si pensamos que los yacimientos neolíticos de Valdivia Oeste y Los Vascos se sitúan a $4 \mathrm{~km}$ aguas arriba en la misma margen derecha del Manzanares (Blasco y Baena 2002: 61, fig. 2.8).

Las observaciones que venimos efectuando no se compadecen bien con algunos planteamientos esgrimidos hasta ahora para este lugar. El marco intelectual en que se inscribe su lectura doméstica (Priego y Quero 1992) ha sido denominado "reflejismo" -reflectionism- (Chapman y Gaydarska 2007: 71-73) y se sustenta en un principio erróneo, la denominada "premisa Pompeya" (Binford 1981; Jiménez Jáimez 2007): la confianza en que el registro arqueológico refleja fielmente áreas de actividad prístinas congeladas en el tiempo. Según esta línea argumental, en la cabaña 013 estaríamos ante el inventario de enseres circulantes en un momento concreto del pasado, abandonados de facto sin llegar a ser desechados y en su contexto primario de consumo; circunstancias idóneas para reconocer asociaciones significativas en términos espaciales y funcionales (Lucas 2012: 102-104). Lamentablemente la realidad es mucho más compleja y tal premisa no funciona en auténticos suelos de habitación ni en la misma ciudad de Pompeya (Chapman y Gaydarska 2007: 72; Lucas 2012: 103). Sin embargo, este prejuicio está muy extendido; el reciente estudio de tres cabañas semiexcavadas de Camino de las Yeseras les adjudica funcionalidades excluyentes - domésticas, funerarias o de reunión comunitariaa partir de su última configuración (Liesau et al. 2013). Cabría apuntar que mientras no se atienda a sus biografías y posibles cambios de uso y se ofrezca información sobre la tafonomía de sus rellenos, éste seguirá siendo un argumento circular.

La principal idea que se desprende de nuestro análisis es la parcialidad del conjunto estudiado, que no constituye una unidad coherente y significativa por sí misma. La cerámica selecta de 1981 poco tiene que ver con el ajuar doméstico representativo de una vivienda de la época, tal como sería usado en su contexto sistémico o vivo. Pero tampoco son estrictamente restos «abandonados in situ, sin que posteriormente se evidencie ni limpieza, ni un excesivo trasiego que modificase su disposición» (Díaz-del-Río 2001: 247). Algunos materiales sí fueron trasegados y no se vislumbran claramente patrones de restos en posición primaria. La colección analizada parece más bien un agregado arbitrario -es decir, cuya asociación no es significativa desde el punto de vista funcional (Lucas 2012: 193198) - de residuos yuxtapuestos resultantes de actividades diversas, con una amplia variabilidad en cuanto a sus procedencias, temporalidad y trayectorias de uso y descarte. La mayor parte de las vasijas comparecen de manera muy incompleta y fragmentaria, con esporádicos remontajes; la gran mayoría $(81 \%)$ de esas porciones son "fragmentos huérfanos", por lo que resulta muy improbable que se rompieran allí mismo. Es por tanto un subproducto muy sesgado por filtros de reducción, selección y representación, tanto naturales como antrópicos. Una porción de los materiales incorporados al registro arqueológico pudo resultar de episodios de consumo celebrados en las cercanías. Porciones de tales vasijas serían arrojadas a los diversos receptáculos según se fueron rellenando, mezcladas con residuos descartados tiempo atrás. Estos procederían de escombreras al aire libre y fueron sometidos a un ciclo predeposicional de duración variable hasta su definitivo acopio y abandono. Es difícil definir con precisión las dinámicas de formación responsables de la imagen presentada. Estas podrían situarse en algún punto intermedio en una escala continua entre polos ideales o extremos (Brudenell y Cooper 2008; Garrow 2012; Lucas 2012: 123). La caracterización aquí esbozada resulta afín al concepto de palimpsesto (Lucas 2012: 112123) y más concretamente al de "palimpsesto acumulativo" (Bailey 2007: 204-205). No interesa tanto la etiqueta como las restricciones que impone ante cualquier interpretación: qué se puede y qué no se puede decir a partir de estos contextos deposicionales.

Por último, la "cabaña 013" ha sido interpretada como «la mayor acumulación de residuos documentada hasta el momento en toda la Meseta» (Díaz-del-Río 2001: 246). Debemos añadir que ese acopio formó parte de una realidad más amplia -y más voluminosa aún-, hasta ahora inadvertida. Su representatividad está mediatizada: a) por su ciclo deposicional, ya que sólo acabaron allí una selección de fragmentos, y b) por la restricción logística del sector excavado, que probablemente afectó a un segmento de foso del que sólo tenemos información parcial (Fig. 1). Las concomitancias de este depósito con la zanja excavada en Las Pozas (Casaseca de las Chanas, Zamora) (Val Recio 1992) ya han sido señaladas (Díaz-del-Río 2001: 237 y 249, nota 116), antes de confirmarse que el yacimiento zamorano es en realidad un recinto de fosos (García García 2013). Los lugares fosados meseteños se vienen datando en el Calcolítico inicial (p.e. Díaz-del-Río 2003; Delibes de Castro et al. 2010), pero su frecuentación 
parece prolongarse hasta los momentos de auge de la vajilla campaniforme (Liesau et al. 2008). Así pues en Las Pozas con seguridad y en El Ventorro de forma hipotética, estaríamos ante recintos fosados cuyas zanjas implicaron el movimiento de grandes volúmenes de sedimento, tanto en vaciarlas como en amortizarlas (Delibes de Castro et al. 2010). La muestra cerámica aquí analizada pudiera comprenderse mejor desde tales dinámicas de colmatado de fosos monumentales. La práctica social tras este fenómeno parece haber sido un tipo de celebraciones periódicas multitudinarias, reproducidas durante la primera mitad del tercer milenio AC (Díaz-del-Río 2001: $249,2003)$. En suma, frente a la lectura inicial de El Ventorro como un poblado permanente y abierto "sin muros ni fosos" (Priego y Quero 1992: 357) nos planteamos la hipótesis opuesta: un lugar delimitado por al menos un foso -interceptado en los sondeos abiertos en los años 1970 y 1980-, para cuyo relleno sería necesaria la agregación de gentes, sin que sea posible asegurar su carácter permanente o episódico. De esta forma acabaron incluidos en él los restos materiales fruto de variadas actividades desempeñadas en su entorno.

\section{Conclusiones y perspectivas}

Este artículo ha presentado una experiencia piloto de limitadas pretensiones y un único objetivo: comprobar la capacidad heurística de la tafonomía orientada a objetos para reinterpretar excavaciones antiguas. El estudio se ha centrado en una muestra representativa de un único tipo de material, registrado al margen de criterios estratigráficos, lo cual limita el alcance de su dictamen, necesariamente no concluyente. Aun así, se ha conseguido caracterizar mejor las dinámicas responsables de la evidencia documentada en la cata de 1981 en El Ventorro. El análisis de las pautas de rotura, erosión y representación de restos cerámicos ha permitido cuestionar la interpretación doméstica de la cabaña 013 y rebatir su carácter primario. Esta zanja podría haber sido un segmento de foso relleno de manera paulatina y deliberada a la par que las fosas anexas, empleando un agregado caótico de restos redepositados que conforman un palimpsesto acumulativo. Numerosas vasijas pudieron emplearse en sucesivos episodios de consumo comunitarios, una pequeña porción de las cuales quedó incorporada a las fosas y zanja inmediatamente tras su rotura. Otra parte son residuos erráticos de más dilatada trayectoria, incluyendo trozos campaniformes y neolíticos y despojos de actividades previas no necesariamente vinculadas -ni espacial ni temporalmente- con tales reuniones y los episodios de vertido a ellas asociados.

A lo largo del estudio la subjetividad del investigador ha sido un prerrequisito $y$ un condicionante en las distintas interpretaciones aquí barajadas, presidiendo tanto el registro de campo en 1981 como la clasificación de la cerámica en 2013, ejercicio no exento de apreciaciones intuitivas y relativas (Edwards 2009: 149). Sin embargo, ha de destacarse el enorme potencial que un enfoque como el aquí apuntado tiene por ofrecer al estudio de la Prehistoria Reciente de la península Ibérica. La cabaña 013 constituye un contexto rico en desperdicios, un tipo de depósitos bien conocidos -basureros, cenizales, vertederos, etc. $-\mathrm{y}$ frecuentes en los yacimientos arqueológicos desde las primeras comunidades agrícolas. Los restos de cultura material contenidos en tales depósitos y sus sedimentos siguen siendo abordados desde estrategias de caracterización tecno-tipológicas y paleoeconómicas (p.e. Chapa et al. 2013). Es hora de afrontar los propios acopios de materiales descartados que encuentra el/la arqueólogo/a por lo que son, y no sólo como fuente de indicios indirectos sobre otras cuestiones. En nuestro estudio de caso, lo idóneo hubiera sido abordar el estudio integral tanto de restos muebles de distinta naturaleza como de la matriz sedimentaria que los envuelve (Lucas 2012: 75 y 114) entendiendo ambas facetas como cultura material en sentido amplio. Así, para aquilatar los ritmos de sedimentación se hubiera requerido un examen pedológico de micromorfología (Courty et al. 1990). La caracterización tafonómica de los materiales líticos y especialmente óseos -tal como se ha efectuado en Camino de las Yeseras (Liesau et al. 2013) - sin duda contribuiría a aclarar las observaciones aquí bosquejadas. Los ejercicios de remontaje combinado de sílex, huesos y cerámica se están mostrando como especialmente diagnósticos para definir las dinámicas deposicionales de un sitio (e.g. Brudenell y Cooper 2008; Beadsmoore et al. 2010). La simple revisión realizada aquí ofrece las ventajas de tener una paleta algo más amplia de opciones interpretativas, ser más consciente de sus limitaciones y haber seguido un protocolo de estudio sistemático y riguroso, que más que resolver dudas ayudara a plantear fórmulas para responderlas en el futuro. Terminamos con las palabras de Orton et al. (1997: 243): «El registro minucioso, rutinario de este tipo de evidencias lleva mucho tiempo, pero habrá ocasiones en las que habrá valido la pena". El/la lector/a sabrá valorar si realmente éste ha sido el caso». 


\section{Notas}

1. Este trabajo se enmarca en el proyecto postdoctoral Past Fragments financiado por la Comisión Europea (Marie Curie Intra-European Fellowship ref. 298285). La colaboración de E. Carmona y C. Vega con el material fue costeada por dicho programa. Sin la eficaz ayuda de A. González Alonso, conservador del Museo de San IsidroMuseo de los Orígenes (Madrid), que puso a nuestra disposición el espacio, infraestructuras, documentación y fondos necesarios, esta investigación hubiera sido impensable. Agradezco los comentarios de los evaluadores de la revista.

2. Además de las piezas citadas en el texto, pudieron reestudiarse los fragmentos de una vasija a mano estampillada (Priego y Quero 1992: fig. 157 y lám. XXVI.1) que parece de la Edad del Hierro y hace dudar de la datación calcolítica de los diversos pies anulares encontrados en el sitio (Priego y Quero 1992: 276, fig. 155), incluido el pie de copa inciso no 23038 clasificado como Ciempozuelos (Priego y Quero 1992: 23 y 235, fig. 119).

\section{Referencias Bibliográficas}

Allen, J.R.L. (1989): A quantitative technique for assessing the roundness of pottery sherds in water contexts. Geoarchaeology, 4: 143-155. DOI: http://dx.doi.org/10.1002/gea.3340040204

Bailey, G. (2007): Time perspectives, palimpsests and the archaeology of time. Journal of Anthropological Archaeology, 26(2): 198-223. DOI: http://dx.doi.org/10.1016/j.jaa.2006.08.002

Beadsmoore, E.; Garrow, D.; Knight, M. (2010): Re-fitting Etton: space, time and material culture within a causewayed enclosure in Cambridgeshire. Proceedings of the Prehistoric Society, 76: 115-134. DOI: http:// dx.doi.org/10.1017/S0079497X00000475

Binford, L.R. (1981): Behavioral Archaeology and the Pompeii premise. Journal of Anthropological Research, 37(3): 195-208. URL estable: www.jstor.org/stable/3629723

Blanco GonzÁlez, A. (e.p.): Sitios en altura y vasijas rotas: reconsiderando la 'plenitud' de Cogotas I (1450-1150 cal AC) en la Meseta. Trabajos de Prehistoria, 71(2).

Blanco González, A.; Chapman, J. (2014): A new method for identifying sherd refits: a case study from the Neolithic of Northumbria, UK. Journal of Field Archaeology, 39(3): 248-255. DOI: http://dx.doi.org/10.1179 /0093469014Z.00000000083.

Blasco, M.C.; Baena, J. (2002): El Marco geográfico. La Colección Bento del Museu d'Arqueologia de Catalunya. Una nueva mirada a la Prehistoria de Madrid (M.C. Blasco coord.), Museu d'Arqueologia de Catalunya, Barcelona: 51-65.

Blasco, M.C.; Baena, J.; Recuero, V. (1994): Los asentamientos. El Horizonte Campaniforme de la Región de Madrid en el centenario de Ciempozuelos (M.C. Blasco ed.), Universidad Autónoma de Madrid, Madrid: 4773.

Blasco, M.C.; Liesau, C.; Ríos, P. (eds.) (2011): Yacimientos calcoliticos con campaniforme de la región de Madrid: nuevos estudios. Universidad Autónoma de Madrid, Madrid.

Bollong, C.A. (1994): Analysis of the stratigraphy and formation processes using patterns of pottery sherd dispersion. Journal of Field Archaeology, 21(1): 15-28. DOI: http://dx.doi.org/10.1179/009346994791549254

Bradley, R.; Fulford, M. (1980): Sherd size in the analysis of occupation debris. Bulletin of the Institute of Archaeology, 17: 85-94.

Brudenell, M.; Cooper, A. (2008): Post-middenism. Depositional histories on Later Bronze Age settlements at Broom, Bedfordshire. Oxford Journal of Archaeology, 27(1): 15-36. DOI: http://dx.doi.org/10.1111/j.14680092.2007.00293.x.

Buko, A. (1998): Pottery, potsherds and the archaeologist: an approach to pottery analyses. Theory and Practice of Archaeological Research (W. Hensel, S. Tabaczyński y P. Urbańczyk eds.), Institute of Archaeology and Ethnology, Varsovia: 381-408.

Byrd, J.E.; Owens JR, D.D. (1997): A Method for Measuring Relative Abundance of Fragmented Archaeological Ceramics. Journal of Field Archaeology, 24(3): 315-320. DOI: http://dx.doi.org/10.1179/009346997792208168

Carmona Ballestero, E. (2013): El Calcolítico en la Cuenca Media del Arlanzón (Burgos, España). Comunidades campesinas, procesos históricos y transformaciones. BAR International Series 2559, Archaeopress, Oxford.

Chapa, T.; Pereira, J.; Cabrera, A.; Charro, C.; Moreno-García, M.; Ruiz, M.; Pérez, S.; López, J.A.; Araujo, R. (2013): Una fosa-vertedero de época vettona en el Cerro de la Mesa (Alcolea de Tajo, Toledo). Trabajos de 
Prehistoria, 70(1): 140-165. DOI: http://dx.doi.org/10.3989/tp.2013.120106

Chapman, J.; Gaydarska, B. (2007): Parts and Wholes. Fragmentation in prehistoric context. Oxbow, Oxford.

Chase, P. (1985): Whole Vessels and Sherds: An Experimental Investigation of their Quantitative Relationships. Journal of Field Archaeology, 12(2): 213-218. DOI: http://dx.doi.org/10.1179/jfa.1985.12.2.213

Courty, M.-A.; Goldberg, P.; Macphail, R. (1990): Soils and Micromorphology in Archaeology. Cambridge University Press, Cambridge.

Delibes de Castro, G.; Crespo Díez, M.; Fernández Manzano, J.; Herrán Martínez, J.I.; Rodríguez Marcos, J.A. (2010): Un recinto de fosos calcolítico en el valle medio del Duero: el Casetón de la Era (Villalba de los Alcores, Valladolid). Actas de las IV Jornadas sobre Patrimonio Arqueológico de la Comunidad de Madrid. Comunidad de Madrid, Madrid: 239-47.

DíAz-DEL-Río, P. (2001): La formación del paisaje agrario. Madrid en el III y II milenios BC. Comunidad de Madrid, Madrid.

Díaz-Del-Río, P. (2003): Recintos de fosos del III milenio a.C. en la Meseta peninsular. Trabajos de Prehistoria, 60(2): 61-78. DOI: http://dx.doi.org/10.3989/tp.2003.v60.i2.81

DíAz-DEL-Río, P. (2006): An appraisal of social inequalities in Central Iberia (c. 5300-1600 cal BC). Social Inequality in Iberian Late Prehistory (P. Díaz-del-Río y L. García San Juan eds.), BAR International Series 1525, Archaeopress, Oxford: 67-79.

Díaz-Del-Río, P.; Vicent García, J. M. (2006): Movilidad, funcionalidad y usos del suelo en la Prehistoria Reciente. Arqueología Espacial, 26: 21-36.

Díaz-del-Río, P.; Consuegra, S.; Peña Chocarro, L.; Márquez, B.; Sampedro, C.; Moreno, R.; Albertini, D.; Pino, B. (1997): Paisajes agrarios prehistóricos en la Meseta peninsular: el caso de 'Las Matillas' (Alcalá de Henares, Madrid). Trabajos de Prehistoria, 54(2): 93-111. URL estable: http://tp.revistas.csic.es/index.php/tp/ article/viewFile/368/372

Edwards, B. (2009): Pits and the architecture of deposition. Narratives of social practice in the Neolithic of North-East England. Tesis doctoral inédita, Durham University, Durham.

EDwARDS, B. (2012): Social Structures: pits and depositional practice in Neolithic Northumberland. Regional Perspectives on Neolithic Pit Deposition. Beyond the Mundane (H. Anderson-Whymark y J. Thomas eds.), Oxbow, Oxford: 77-99.

Fabián García, J.F. (2006): El IV y III milenio a.C. en el Valle del Amblés (Ávila). Junta de Castilla y León, Valladolid.

García Barrios, A.S. (2004-2005): El espacio doméstico en la Prehistoria Reciente de la Meseta: el testimonio de las cabañas de la Edad del Cobre en el Valle Medio del Duero. Lancia, 6: 59-75.

García García, M. (2013): Las Pozas (Casaseca de las Chanas, Zamora): dos nuevos recintos de fosos calcolíticos en el Valle del Duero. Trabajos de Prehistoria, 70(1): 175-184. DOI: http://dx.doi.org/10.3989/tp.2013.12108

García Rosselló, J.; Calvo Trias, M. (2013): Making Pots: el modelado de la cerámica a mano y su potencial interpretativo. BAR International Series 2540, Archaeopress, Oxford.

Garrido Pena. R. (1997): Bell Beakers in the Southern Meseta of the Iberian Peninsula: socioeconomic context and new data. Oxford Journal of Archaeology, 16(2): 187-209. DOI: http://dx.doi.org/10.1111/1468-0092.00034

Garrido Pena, R. (2000): El Campaniforme en la Meseta Central de la Península Ibérica (c. 2500-2000 a.C.). BAR International Series 892, Archaeopress, Oxford.

Garrow, D. (2010): The Temporality of Materials: Occupation Practices in Eastern England during the $5^{\text {th }}$ and $4^{\text {th }}$ millennia BC. Landscapes in Transition (B. Finlayson y G. Warren eds.), Oxbow, Oxford: 208-220.

GARRow, D. (2012): Odd deposits and average practice: a critical history of the concept of structured deposition. Archaeological Dialogues, 19(2): 85-115. DOI: http://dx.doi.org/10.1017/S1380203812000141

Garrow, D.; Beadsmoore, E.; Knight, M. (2005): Pit clusters and the temporality of occupation: an Earlier Neolithic site at Kilverstone, Thetford, Nordfolk. Proceedings of the Prehistoric Society, 71: 139-57. DOI: http://dx.doi.org/10.1017/S0079497X00000980

Harrison, R.; Quero, S.; Priego, M.C. (1975): Beaker metallurgy in Spain. Antiquity, 49: 273-280.

Harrison, R.J. (1977): The Bell Beaker Cultures of Spain and Portugal. Harvard University, CambridgeMassachussets.

Harrison, R.J.; Mederos, A. (2001): Bell Beakers and Social Complexity in Central Spain. Bell Beakers today. Pottery, people, culture, symbols in prehistoric Europe (Riva del Garda, 1998) (F. Nicolis ed.), Provincia Autonoma di Trento, Trento: 111-124. 
Hodder, I. (1999): The Archaeological Process. Blackwell, Oxford.

Jiménez JÁimez, V. (2007): La Premisa Pompeya y las ‘cabañas semisubterráneas’ del sur de la Península Ibérica (IV-III milenios AC). Mainake, 29: 475-492.

JiMÉNEZ JÁIMEZ, V. (2008): El ciclo formativo del registro arqueológico. Una alternativa a la dicotomía deposicional/ posdeposicional. Zephyrus, 62(2): 125-137. URL estable: http://campus.usal.es/ revistas_trabajo/index. php/0514-7336/article/view/1091/1169

Jiménez Jáimez, V.; Márquez Romero, J.E. (2006): Aquí no hay quien viva. Sobre las casas-pozo en la Prehistoria de Andalucía durante el IV y III milenios AC. Spal, 15: 39-49.

Johnson, M. (2006): On the Nature of Theoretical Archaeology and Archaeological Theory. Archaeological Dialogues, 13(2): 117-132. DOI: http://dx.doi.org/10.1017/S138020380621208X

Liesau, C.; Rios, P.; Aliaga, R.; Daza, A.; Llorente, L.; Blasco, C. (2013): Hut structures from the Bell Beaker horizon: housing, communal or funerary use in the Camino de las Yeseras site (Madrid). Current researches on Bell Beakers. Proceedings of the 15th International Bell Beaker Conference: From Atlantic to Ural (May 2011, Poio, Pontevedra) (M.P. Prieto y L. Salanova coords.), Galician ArchaeoPots, Santiago de Compostela: 139-151.

Liesau, C.; Blasco, C.; Ríos, P.; Vega, J.; Menduiña, R.; Blanco, J. F.; Baena, J.; Herrera, T.; Petri, A.; Gómez, J. L. (2008): Un espacio compartido por vivos y muertos: El poblado calcolítico de fosos de Camino de las Yeseras (San Fernando de Henares, Madrid). Complutum, 19(1): 97-120. URL estable: http://revistas.ucm.es/ index.php/CMPL/article/viewFile/CMPL0808110097A/29274

LucAs, G. (2012): Understanding the Archaeological Record. Cambridge University Press, Cambridge.

Muñoz, K. (1999): La Prehistoria Reciente en el Tajo Central (cal V-I Milenio a.C.). Complutum, 10: 91-122.

Orton, C.; Tyers, P.; Vince, A.G. (1997): La Cerámica en Arqueología. Crítica, Barcelona.

Priego, M.C.; Quero, S. (1977): El Campaniforme en el Valle del Manzanares (Madrid). Actas del XIV Congreso Nacional de Arqueología, Vitoria: 267-276.

Priego, M.C.; Quero, S. (1983): Actividades de la sección arqueológica del museo municipal durante 1982. Estudios de Prehistoria y Arqueología Madrileñas, 2: 285-314.

Priego, M.C.; Quero, S. (1992): El Ventorro, un poblado prehistórico de los albores de la metalurgia. Estudios de Prehistoria y Arqueología Madrileñas 8, Ayuntamiento de Madrid, Madrid.

Quero, S.; Priego, M.C. (1975): Noticia sobre el poblado campaniforme de El Ventorro (Madrid). Zephyrus, 26: 321-329. URL estable: http://revistas.usal.es/index.php/0514-7336/article/view/470/642

Quero, S.; Priego, M.C. (1978): Campaniformes de la Meseta en el Instituto Arqueológico Municipal de Madrid. Revista de Archivos, Bibliotecas y Museos del Ayuntamiento de Madrid, 3-4: 83-94.

Ríos, P. (2011): El medio físico. Análisis preliminar de los recursos naturales del III milenio a.C. en la región de Madrid. En Blasco, Liesau y Ríos 2011: 31-72.

Rodríguez Marcos, J.A. (2005): Una cabaña de época campaniforme: el yacimiento de Pico de Castro (Quintanilla de Arriba, Valladolid). Estudios de Historia y Arte: homenaje al profesor Alberto C. Ibáñez Pérez (L.S. Iglesias, J. Payo y M.P. Alonso eds.), Universidad de Burgos, Burgos: 81-86.

Rojo Guerra, M.A.; Garrido Pena, R.; García Martínez, I. (2005): El Ventorro (Madrid). El Campaniforme en la Península Ibérica y su Contexto Europeo (M.A. Rojo, R. Garrido, R. e I. García eds.), Universidad de Valladolid, Valladolid: 525-533.

SÁnchez-Polo, A. y Blanco-González, A. (2014): Death, Relics and the Demise of Huts. Patterns of Planned Abandonment in Middle BA Central Iberia (Spain). European Journal of Archaeology, 17(1): 4-26. DOI: http://dx.doi.org/10.1179/1461957113 Y.0000000048

Schiffer, M.B. (1987): Formation Processes of the Archaeological Record. New Mexico University Press, Alburquerque.

Schiffer, M.B.; Skibo, J. M. (1989): A provisional theory of ceramic abrasion. American Anthropology, 91(1): 101-115. DOI: http://dx.doi.org/10.1525/aa.1989.91.1.02a00060

Skibo, J.M. (1992): Pottery Function. A Use-Alteration Perspective. Plenum Press, Nueva York.

Solneim, W.G. (1960): The Use of Sherd Weights and Counts in the Handling of Archaeological Data. Current Anthropology, 1: 325-329.

Sørensen, M.L.S. (1996): Pottery evidence for formation process in the Late Bronze Age deposits. Refuse and Disposal at Area 16 East Runnymede (S. Needham y T. Spence coords.), volumen 2, British Museum Press, London: 61-73. 
Val ReCio, J. Del (1992): El yacimiento calcolítico precampaniforme de Las Pozas en Casaseca de las Chanas (Zamora). Boletín del Seminario de Estudios de Arte y Arqueología, 58: 47-62.

Wolfram, S. (2013): Two sides of the coin: ceramic taphonomy and domestic space in the Linear Pottery settlements Hanau-Klein-Auheim and Eythra (Germany). The Domestic Space in LBK Settlements (C. Hamon, P. Allard y M. Ilett eds.), Verlag Marie Leidorf GmbH, Rahden/Westf: 79-90.

Yravedra Sainz de los Terreros, J. (2013): Tafonomía aplicada a Zooarqueología. Universidad Nacional de Educación a Distancia, Madrid. 